\title{
Challenges to Climate Planning in Rural Inland Florida and Recommendations for Future Actions
}

\author{
Lacey Lingelbach \\ College of Agricultural and Life Sciences
}

Faculty Mentor: Cynthia Barnett, College of Journalism and Communications

\begin{abstract}
Despite being farther away from direct impacts of sea-level rise, Florida's rural inland localities, like those across the nation and world, can be as vulnerable to a changing climate as coastal ones. However, unlike their urban coastal peers, many have not addressed or acknowledged climate change. Few existing research projects have explored the reasons why. To begin filling the knowledge gap and understanding the complexities of the rural Florida climate story, this research aims to answer the question: What challenges are preventing rural inland communities in Florida from addressing climate change, and what do they need to overcome them? To characterize these obstacles and identify next steps, a combination of primary (i.e. surveys) and secondary sources from the author, government agencies, scientists, universities, and other expert organizations were analyzed holistically. The four challenges identified include: community sentiment, investment capacity, gaps in climate literacy, and external connections and coordination. These challenges are linked to numerous underlying issues characteristic of rural communities, such as socioeconomic levels, physical and social isolation, the availability of human capital, and cultural values and perceptions. Based on this information, the discussion section reviews how various stakeholders - local governments, community members, and external supporting agents - can actively curtail disparities in climate preparedness.
\end{abstract}

Keywords: climate change, climate action, rural, Florida

\section{Introduction}

Changes to the climate are already disrupting communities across Florida (Environmental Protection Agency, 2016). Climate models project impacts will escalate in the future with increasing temperatures, rising sea levels, warming oceans, variable precipitation and drought events, and intensified tropical storms (Carter et al., 2018; Runkle et al., 2017). Due to their dependence on natural resources, economic issues, and poor access to health care, rural inland areas in the panhandle, north central, and south central regions of Florida are particularly vulnerable to such impacts (Grant \& Bonveccio, 2019; Hales et al., 2014; UF Bob Graham Center [BGC], 2020). Compared to their urban and suburban counterparts, these communities, 
especially in North Central and Northwest Florida, have adopted few, if any, climate preparedness and planning strategies (BGC, 2020). There is limited research on the lack of rural Florida climate action. However, without understanding their story, these areas can get left behind and remain susceptible to social, economic, and physical climate effects. Based on community perspectives and other secondary data, this research answers the question: What challenges are preventing rural inland communities in Florida from addressing climate change, and what do they need to overcome them?

\section{Methods and Materials}

Over the past year and a half, quantitative and qualitative materials were collected by the author. The sources of information used for this paper include the following:

- Florida Local Government Climate Policy Needs Assessment Survey. The author created this survey for UF/IFAS Extension and Florida Sea Grant to understand local government climate attitudes and resource needs. From May to July 2020, 24 survey questions related to climate science knowledge, concern, actions, challenges, and interests were administered via the Qualtrics platform to counties and incorporated municipal governments across Florida. In total, a diverse group of representatives from 128 Florida counties and municipalities of varying population sizes completed the survey. At least one county and one municipality responded from each region of Florida, with the majority derived from the Southeast, Tampa Bay, and East Central areas.

- Bob Graham Center's 2020 Barometer Florida Project. Along with other undergraduate "Civic Scholars" chosen for the Barometer Florida project, the author analyzed local climate impacts and actions in Florida's 67 counties. The project provides county-level data related to health, climate, vulnerability, and community as well as regional data snapshots.

For the purposes of this research, rural inland communities are defined as those in (a) noncoastal counties with 125,000 people or fewer, or (b) coastal, suburban, or urban counties at least 20 miles from the coast with an average population between 5,000 to 10,000 (Office of Policy Planning, 2018). Using this definition, the Needs Assessment Survey and Barometer Florida tool both helped identify prominent barriers for implementing climate strategies and feedback on 
possible solutions. Additionally, research from other credible primary and secondary sources further contextualized the results to rural areas and provided ideas of the next steps actors can take.

\section{Results and Analysis}

The following four challenges were identified through the materials. They are characterized and analyzed for their possible causes. Each of them builds upon the others in a complex cyclical relationship.

\section{Challenge One: Community Sentiment}

The attitude towards climate change and its local consequences varies between rural and urban communities. When asked about the prioritization of climate change in the local government entity, $63 \%$ of responses, primarily from large coastal cities, designated it as 'high' or 'moderate' (Lingelbach, 2020). Yet, small communities of rural counties, like Franklin and Desoto, as well as coastal ones, like Volusia and Duval, denoted climate change as a low to non priority issue (Lingelbach, 2020). Other studies have shown that, opposite of their urban and suburban peers, U.S. rural residents rank other environmental issues, such as clean water and farmland conservation, higher than climate change (Pechar Diamond et al., 2020). Thus, this work is consistent with previous studies in suggesting that rural inland Florida has lower public sentiment and political will for climate planning than other types of communities.

However, this does not necessarily mean that rural Floridians "deny" climate issues. The Needs Assessment Survey (2020) asked participants about their localities' impressions of climate-related projections and impacts. As shown in Figures 1 and 2, the highest concern (47.66\% of survey respondants) is for intensified extreme weather events, like tropical storms, and climate consequences related to increased costs to maintain infrastructure (23.98\% of survey respondants), loss of natural resources or ecosystem services (18.42\% of survey respondants), and economic loss (17.84\% of survey respondants). Although these results are from all types of Florida governments, rural ones are likely attentive to these same impacts as well. Other research found that rural residents are conscious of climate and environmental vulnerabilities and support climate policies that address extreme weather events, protect environmental resources, and offer economic aid to farmers (Bonnie et al., 2020; Pechar Diamond et al., 2020). Hence, rural 
communities have dynamic climate opinions where they do care about potential impacts but the salience of the issue remains low.
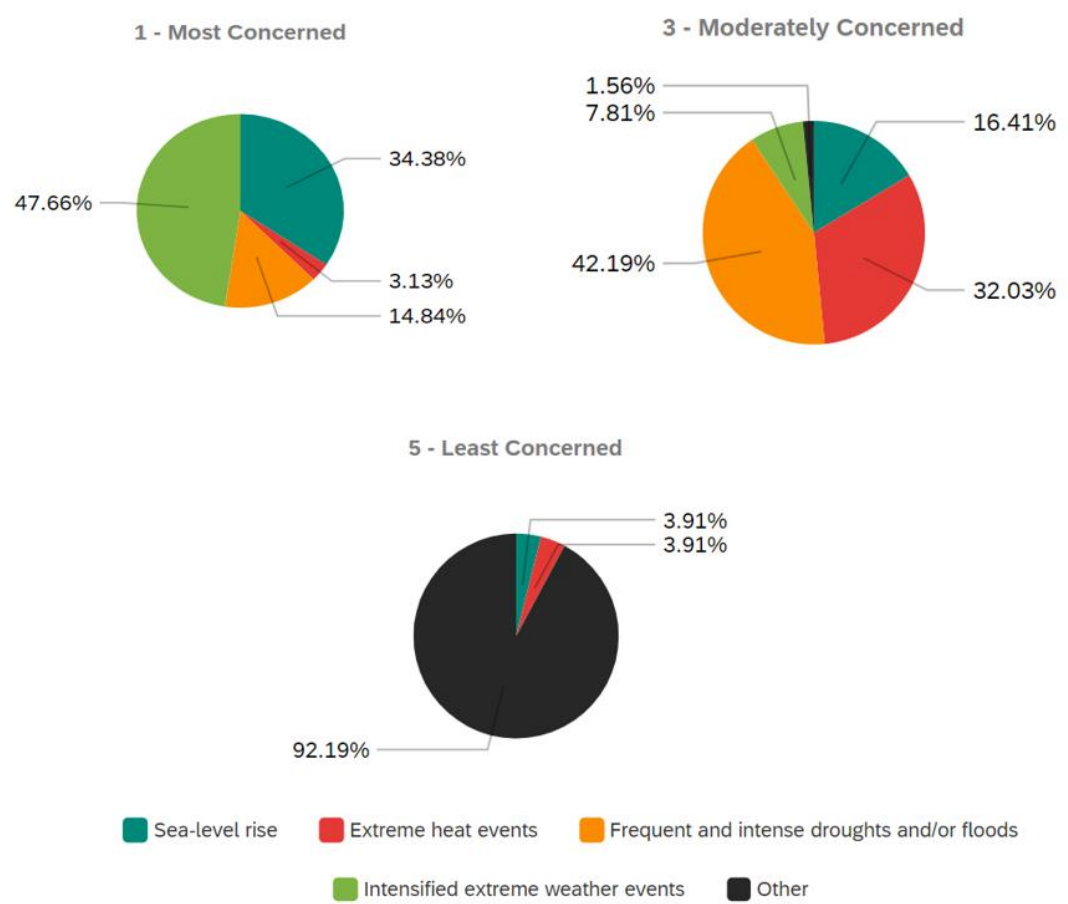

Figure 1. Pie Charts of the Level of Concern for Climate Projections among Florida Local Governments. Adapted from "Florida Local Government Climate Policy Needs Assessment Survey" by L. Lingelbach, 2020. Copyright 2020 by UF/IFAS Extension and Florida Sea Grant.

\section{What factors contribute to the lack of urgency in rural climate attitudes?}

Perception of climate risks. The closer people live to the coast, 25 miles or less, the more they perceive climate change affecting their community (Kennedy, 2020). Distance adds to difficulty in physically seeing the prevalence of climate change in the community, especially with the focus on sea level rise (Lingelbach, 2020).

Disconnects between the local community and climate science. Rural residents are often skeptical of connections between extreme weather and climate change (Lingelbach, 2020; Pechar Diamond et al., 2020). Disagreements with climate science stems from the lack of locally specific climate information, political polarization, and strained relationships with external experts (Bonnie et al., 2020; Hauser \& Jadin, 2012; Lingelbach, 2020). 

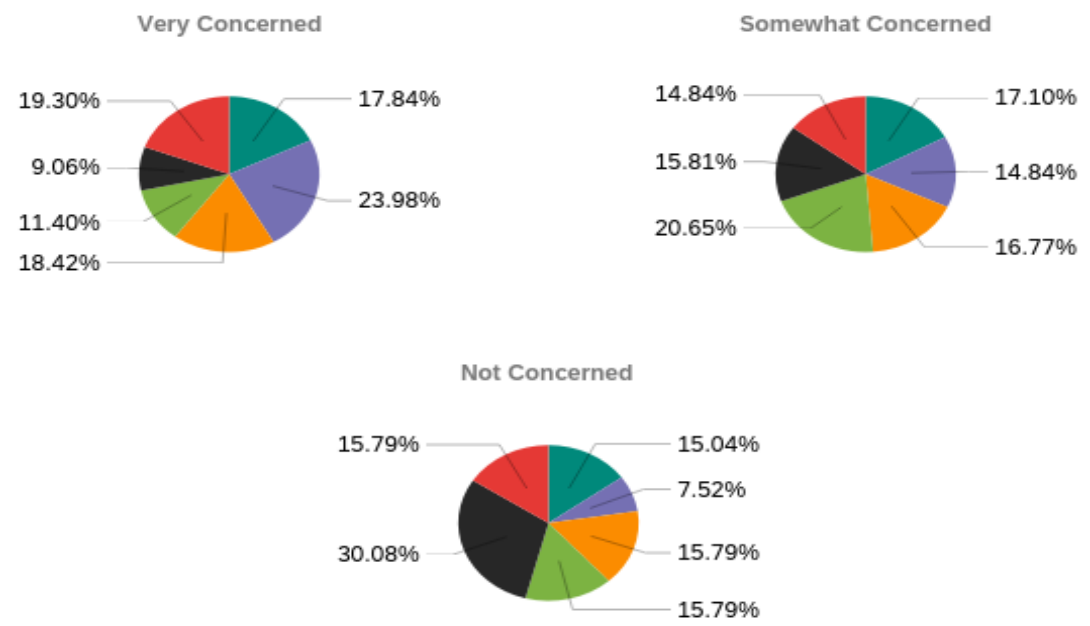

Economic loss Public and/or private infrastructure maintenance costs

Impacts to the housing market Impacts to public health

Impacts to social equity

Loss of natural resources and/or ecosystem services

Figure 2. Pie Charts of the Level of Concern for Climate Change Impacts among Florida Local Governments. Adapted from "Florida Local Government Climate Policy Needs Assessment Survey" by L. Lingelbach, 2020. Copyright 2020 by UF/IFAS Extension and Florida Sea Grant.

\section{Challenge Two: Investment Capacity}

Climate action requires varying investments of both human and financial resources. As pictured in Figure 3, similar to the "lack of political will/public sentiment" (20\% of survey respondants, orange) discussed in challenge one, deficient staff (33\% of survey respondants, red) and financial capacity ( $21 \%$ of survey respondants, blue-green) also pose large barriers to climate planning for all types of local governments in Florida based on the Needs Assessment Survey. Relative to urban areas, rural local governments and community organizations struggle more because they have less available investment capital. For instance, with smaller populations, rural counties and municipalities have a smaller tax base and constrained budgets (Hales et al., 2014). Without financial resources, there are fewer staff members and departments, and those who are employed are already performing highly involved jobs (Hauser \& Jadin, 2012; Lingelbach, 2020). So, it is difficult to assign new roles to staff. Furthermore, although local rural residents and businesses supply additional services in place of local government (e.g. all- 
volunteer fire departments), their sentiment towards climate change influences their resource expenditures (Hauser \& Jadin, 2012).

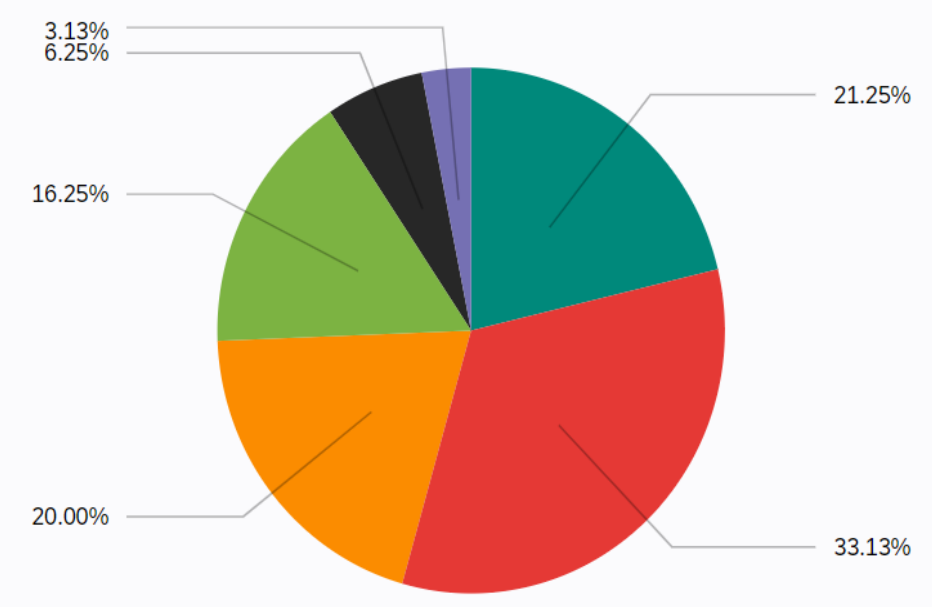

Financial Lack of staff capacity Lack of political will/public sentiment or not a priority issue

Not knowing where to begin or what climate policy looks like

Legal issues or concerns

Other

Figure 3. Graph of Barriers to Implementing Climate Action in Florida Local Governments. Adapted from "Florida Local Government Climate Policy Needs Assessment Survey" by L. Lingelbach, 2020. Copyright 2020 by UF/IFAS Extension and Florida Sea Grant.

\section{What factors contribute to strained rural investment capacity?}

Existing socioeconomic difficulties. In Florida, the rural poverty rate of $18.8 \%$ is higher than the urban one of $12.6 \%$ (USDA Economic Research Service, 2021). Poverty and related issues prevent rural citizens, especially historically marginalized ones, from committing sufficient time or financial resources to be involved in community planning and volunteering (Grant \& Bonveccio, 2019). Additionally, economic and social disparities with current observable impacts are of high priority to rural policymakers and community members than climate change (Hales et al., 2014).

External Aid. Rural communities' physical and digital isolation makes it difficult to receive or know about opportunities offered by outside groups, like grants and loans (Grant \& Bonveccio, 2019). Also, some external supporting agents, like the State of Florida, design 
resources specific for coastal areas only so there is often less available aid to rural residents (Florida Department of Environmental Protection, 2020).

Awareness of Innovative Solutions. Many climate solutions are framed as large-scale urban investments by advocacy groups, scientists, and the federal government. For example, a common mitigation suggestion is to improve access to public transit and create bike-sharing programs, but rural communities do not often have public transportation infrastructure. Accordingly, small local governments are unaware of solutions to enact that fit the needs, priorities, and resources of their community (Lingelbach, 2020).

\section{Challenge Three: Gaps in Climate Literacy}

Since their livelihoods depend on natural resources, rural individuals are informed about environmental issues occurring in their surrounding ecosystems (Bonnie et al., 2020; Hauser \& Jadin, 2012). Moreover, people within local government and the community, like utility workers, land-use planners, and agriculturalists, possess technical skills from using environmental and climate data (Bonnie et al., 2020). In spite of this general understanding of the environment, climate knowledge is more deficient in rural communities in three ways.

The Carbon Cycle. In Figure 4, "sources and sinks of greenhouse gases", like carbon dioxide, are shown to be less understood than other climate science principles. Some text-entry responses from the Needs Assessment Survey (2020) noted little awareness of the role humans play in the transfer and accumulation of carbon. As previously mentioned in challenge one, rural residents typically do not connect everyday life to impacting the climate or to extreme changes occuring today (Bonnie et al., 2020; Lingelbach, 2020). So, it is likely that rural areas, especially, are unaware of various influences on the carbon cycle, especially from their own actions.

Using Climate Models. Climate models are essential for obtaining climate information and implementing solutions. As indicated by the purple bar in Figure 4, local government operants in Florida are least familiar with using these tools. Some text-entry responses in the Needs Assessment Survey (2020) noted issues with choosing the right climate model for their community or interpreting them to identify social and economic vulnerabilities.

Climate Solutions. As depicted in Figure 3, "not knowing where to start or begin" ranked relatively high as a barrier for climate policy implementation on the Needs Assessment Survey, particularly for rural inland areas in counties like Alachua, Washington, and Madison, and 
Highlands. Similarly, farmers across the United States are unable to scale up their adaptation actions because they are uncertain of cost-effective and environmentally friendly solutions (Hales et al., 2014). So, among rural stakeholders, there is a need for technical information on best climate management practices and planning under various climate scenarios (Lingelbach, 2020).

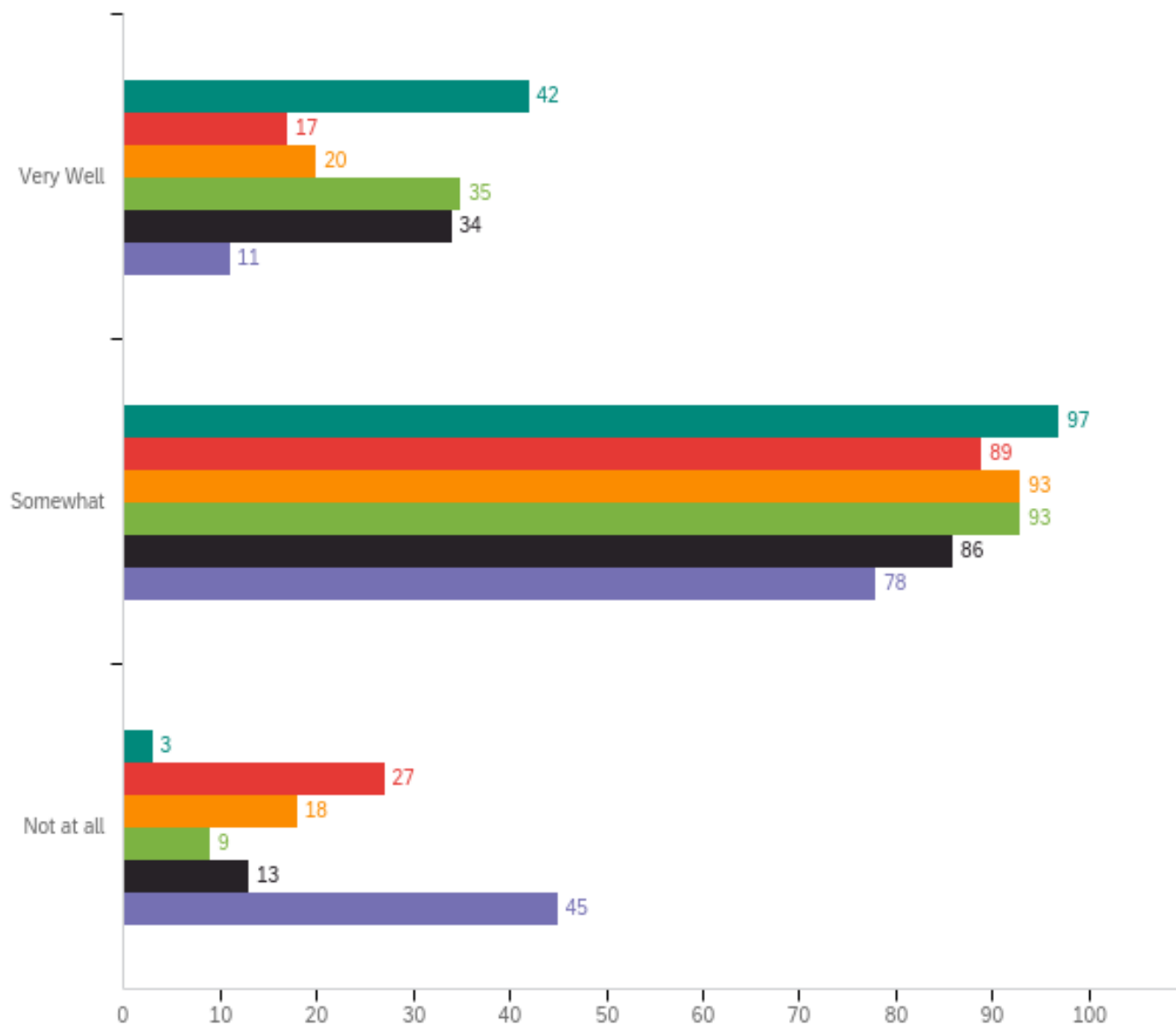

The difference between weather and climate $\square$ Sources and sinks of greenhouse gases

The role of the ozone layer Indicators of climate change

Evidence of human actions contributing to climate change Climate models and their uses

Figure 4. Graph of Self-Reported Knowledge Levels for Climate Science Concepts among Florida Local Governments per number of respondants. Adapted from "Florida Local Government Climate Policy Needs Assessment Survey" by L. Lingelbach, 2020. Copyright 2020 by UF/IFAS Extension and Florida Sea Grant. 


\section{What factors contribute to rural gaps in climate knowledge?}

Access to Training Resources and Climate Information. Training and educating rural experts and stakeholders requires additional time, finances, and staff capacity that many rural communities do not have (Hales et al., 2014; Lingelbach, 2020). Moreover, climate information is often provided in inopportune and exclusionary formats for small rural towns that are physically and digitally isolated (Grant \& Bonveccio, 2019). For instance, conferences and workshops hosted by climate researchers and policymakers are primarily held in coastal areas or large urban cities, while climate data is accessible through internet services.

Limited Use of Available Climate Data. Locally specific climate information is often insufficient to meet the needs of rural communities (Hauser \& Jadin, 2012). In particular, climate data and projections are primarily available at global, regional, or statewide scales because of the technical challenges and financial costs of downscaling climate models (Hales et al., 2014). Without more specific local data, rural stakeholders may struggle to connect observed changes to local activities and conditions as well as find solutions appropriate for their climate situations.

\section{Challenge Four: External Connections and Coordination}

External agents, like those from federal and state agencies, nearby communities or counties, nonprofits and businesses, academic institutions, and environmental advocacy organizations, offer direct and indirect financial, technical, and advisory support to both local governments and community stakeholders pursuing climate action (Hauser \& Jadin, 2012). In return, these external groups can address climate impacts at the multiple scales on which they occur and attain their own adaptation and mitigation goals (Hauser \& Jadin, 2012). External agents already collaborate with Florida's rural communities to address healthcare access, economic development, natural resource industries, and other priorities. However, climate collaboration is rarer. Rural residents report feeling more excluded and detached from extraneous climate planning opportunities and materials (Hauser \& Jadin, 2012; Lingelbach, 2020; Pechar Diamond, 2020). This research found that the largest rural disconnect is felt with federal agencies, the state government, regional networks, and counties. 


\section{What factors contribute to weak interactions between external agents and rural areas?}

Physical and Digital Isolation. Given limited access to major forms of public transportation, like buses, in North Central, Northwestern, and South Central Florida, meeting with outside experts is challenging (Guitierrez \& LeProvost, 2016). Although the COVID-19 pandemic has increased the use of online networking opportunities, rural areas also have poor access to reliable and affordable high-speed Internet (Guitierrez \& LeProvost, 2016). Thus, external connections are strained from the characteristic remoteness of rural communities.

Mistrust in Outside Groups. Rural residents are more wary of external agents, like federal and state elected officials, due to their historical exclusion from policy considerations and conversations (Bonnie et al. 2020; Lingelbach; 2020). However, they are more accepting of external groups that are integrated into the local social network (Clayton et al., 2016). For instance, they are shown to trust information from some government agencies that are more present and supportive of rural communities such as the US Department of Agriculture and U.S. Fish and Wildlife Service (Bonnie et al., 2020). Furthermore, in the Needs Assessment Survey (2020), the Florida League of Cities, Florida Association of Counties, and UF/IFAS Extension are the primary sources of climate information for small Florida communities with populations below 1,000. Small rural towns and counties are members of the first two groups; and, rural residents often use UF/IFAS Extension services to guide decisions pertaining to agriculture, the natural environment, and family resources (Hauser \& Jadin, 2012; Lingelbach, 2020).

Misunderstanding between the Two Entities. Because rural voters are often viewed as unconcerned with climate issues or the environment, outside groups may not see the benefits of engaging them on climate action (Bonnie et al., 2020). However, leaving them out of such conversations induces rural residents to feel wary about climate and environmental issues and develop negative perceptions of such groups (Bonnie et al., 2020).

\section{Discussion}

The following recommendations were designed to overcome the challenges of low political salience and public will, reduced resource investment capacity, knowledge gaps of climate science and solutions, and issues working with external agents. Since rural residents are more supportive of local climate policy authority and local groups are more trusted, these suggestions rely on them to implement climate strategies according to the needs and values of their 
community (BGC, 2020; Bonnie et al., 2020; Clayton, 2016). Many residents are already resilient and strong in the face of environmental, economic, and social issues, and they are interested in learning about actions they can take now. To support these local actors, governments and other external agents must actively work to minimize barriers while allowing local communities to make their own decisions (Hauser \& Jadin, 2012). In other words, through a dialogue among local governments, community members, and outside groups, communities can become more aware and capable of managing local climate impacts.

\section{$\underline{\text { Local Governments }}$}

\section{Professional Training and Climate Leadership}

- Train staff on adaptive management skills and climate planning tools.

- Establish leadership for overseeing climate strategies either within local government (e.g. departments or staff members) or with community leaders via task forces and advisory boards.

- Perform a vulnerability assessment to prioritize climate actions according to the needs of citizens and community assets, quantified at-risk populations, and local resource capacity.

- Integrate climate considerations into existing operations, such as disaster preparedness procedures, comprehensive plans, natural resource management decisions, economic development and social equity initiatives, and other overlapping goals.

\section{Community Learning}

- Host inclusive, collaborative community dialogues on local climate impacts and solutions aimed at empowering vulnerable populations.

- Provide climate learning opportunities inside and outside the classroom to K-12 students through the school district.

\section{Local and Regional Coalitions}

- Form a local resource alliance with community stakeholders, businesses, and agencies in the existing social networks (e.g. the county and taxing districts) to finance climate solutions, gather local climate data, access additional resources, receive feedback on policy solutions, and coordinate climate actions. 
- Strengthen external partnerships with other nearby governments and community-based organizations by creating or joining a rural coalition similar to the South Florida Regional Climate Compact or the Rural Climate Network.

\section{Community Stakeholders and Organizations}

\section{Community-Led Climate Efforts}

- Participate in individual, organizational, community-wide, and large-scale climate action opportunities. Examples of such action include:

$\bigcirc$ performing self vulnerability assessments,

$\bigcirc$ serving on advisory boards,

$\bigcirc \quad$ attending skill training sessions, and

- engaging in resiliency planning dialogues.

\section{Climate Communication and Activism}

- Lead community climate conversations and build local coalitions by capitalizing on existing social connections.

- Advocate through grassroots activism that local, state, and federal governments acknowledge rural climate impacts, use a participatory policy process, and aid in the adoption of local climate policy.

\section{Financial and Technical Support}

- Form public-private partnerships through locally based businesses and business associations.

- Share localized data and climate science information collected from daily observations by farmers and other local experts.

- Use organizational connections to expand access to outside groups and devise large-scale partnerships.

\section{External Actors}

\section{Rural Climate Resources}

- Cater climate information to the vulnerabilities, values, and wants of rural inland communities. 
- Provide similar or expand existing incentive, grant, and assistance programs, training opportunities, and consulting services offered to coastal and urban communities.

- Develop additional climate financing options for local entities and individual stakeholders through environmental finance groups, banks, insurance companies, or realestate markets.

\section{Sharing Resources}

- Administer information and services in affordable and accessible formats.

- Aggregate tools, case studies, template ordinances and plans, and best management practices specific to rural stakeholders into a single online database.

- Distribute information in partnership with or through trusted sources.

\section{Community Interactions}

- Communicate clearly with messages that connect to local values and focus on solutions.

- Cultivate relationships with community champions and experts to build support for action, better understand local climate impacts, and strengthen trust networks.

\section{Conclusion}

This research identified that the lack of rural climate action is related to community sentiment, investment capacity, gaps in climate literacy, and external connections and coordination. Due to their geographical, social, and economic characteristics, rural inland areas have less access to resources and technical skills to implement adaptation and mitigation strategies. The non-urgent and disconnected climate narrative in these regions decreases the priority to invest in rural climate resources and plans. Additionally, rural stakeholders are often excluded from climate engagement efforts and resources by major players including state and federal government, business investors, non-profits, and climate scientists.

There are some limitations to these findings including: (1) inherent survey bias, (2) measuring only the perceptions of government employees across all of Florida, (3) reliance on national characterization of rural values and socioeconomic demographics, and (4) national and statewide information gaps on rural climate action. So, there may be other challenges or contributing factors that are not detected in this paper. Future research should address these challenges by surveying rural Florida residents, organizations, and governments, especially those in low-income areas, through in-person and online communication methods. These perspectives 
can provide more specific information on the rural sentiment, technical skills, and climate action. Moreover, investigating the reason for scant rural engagement by various climate-focused agencies and non-governmental organizations can help elucidate the role of external actors. Nonetheless, this research has begun characterizing the rural Florida climate story as well as identified future steps to continue these efforts and ignite local climate action.

\section{Acknowledgements}

I would like to thank those who contributed to this research. To my faculty mentor, Cynthia Barnett, I appreciate the time you took to encourage, edit, and advise me as I pursued this project. I would also like to express my gratitude to the Bob Graham Center for Public Service and the Florida Climate Institute for sponsoring this project. Furthermore, I appreciate the key data provided by the UF/IFAS Extension and Florida Sea Grant staff as well as all the local government employees that responded to the Needs Assessment Survey despite the difficulties added in doing so from the COVID-19 pandemic.

\section{References}

Bonnie, R., Pechar Diamond, \& E., Rowe, E. (2020). Understanding rural attitudes toward the environment and conservation in America (NI Report 20-03). Nicholas Institute for Environmental Policy Solutions. https://nicholasinstitute.duke.edu/sites/default/files/publications/understanding-rural-attitudestoward-environment-conservation-america.pdf

Carter, L., Terando, A., Dows, K., Hiers, K., Kunkel, K.E., Lascurain, A., Marcy, D., Osland, M., \& Schramm, P. (2018). Southeast. In D.R. Reidmiller, C.W. Avery, D.R. Easterling, K.E. Kunkel, K.L.M. Lewis, T.K. Maycock, \& B.C. Stewart (Eds.), Impacts, risks, and adaptation in the United States: Fourth national climate assessment, volume II (pp. 743-808). U.S. Global Change Research Program. https://doi.org/10.7930/NCA4.2018.CH19

Clayton, S., Silka, L., Trott, C., Chapman, D., \& Mancoli, S. (2016). Building resilient communities in the face of climate change: A resource for local communities. The Society for the Psychological Study of Social Issues. https://www.spssi.org/index.cfm?fuseaction=document.viewdocument\&ID=3F28EB86AE4CA3 BB2EE025BE0093BF04C3C86089AFFADC9117681192CC17EABCA6952AE18DBE281F122 D1C5A3A1CBAA2

Environmental Protection Agency. (2016). What climate change means for Florida. https://www.epa.gov/sites/production/files/2016-08/documents/climate-change-fl.pdf

Florida Department of Environmental Protection. (2020). FRCP Resilience Grants. https://floridadep.gov/rcp/florida-resilient-coastlines-program/content/frcp-resilience-grants

Grant, S \& Bonveccio, A. (2019). Coastal justice: Climate change and social resilience in Florida [White paper]. University of Florida Levin College of Law. https://www.law.ufl.edu/law/wpcontent/uploads/Sekita-Grant-Coastal-Justice-White-Paper.pdf 
Gutierrez, K. S., \& LePrevost, C. E. (2016). Climate justice in rural Southeastern United States: A review of climate change impacts and effects on human health. International journal of environmental research and public health, 13(2), 189. https://doi.org/10.3390/ijerph13020189

Hales, D., Hohenstein, W., Bidwell, M., Landry, C., McGranahan, D., Molnar, J., Morton, L. W., Vasquez, M., \& Jadin, J. (2014). Rural Communities. In J. M. Melillo, T.C. Richmond, \& G. W. Yohe (Eds.), Climate change impacts in the United States: The third national climate assessment (pp. 339 - 349). U.S. Global Change Research Program. https://doi.org/10.7930/J01Z429C

Hauser, R. \& Jadin, J. (2012). Rural Communities Workshop Technical Report to the 2013 National Climate Assessment. U.S. Global Change Research Program. https://downloads.globalchange.gov/nca/technical inputs/rural-communities-workshop-technicalinput.pdf

Kennedy, B. (2020, June 29). Most Americans say climate change affects their local community, including $70 \%$ living near coast. Pew Research Center. https://www.pewresearch.org/facttank/2020/06/29/most-americans-say-climate-change-impacts-their-community-but-effects-varyby-region- 21

Lingelbach, L.A. (2020). Florida Local Government Climate Policy Needs Assessment Survey [Unpublished raw data]. UF/IFAS Extension \& Florida Sea Grant.

Office of Policy Planning. (2018). Florida's rural areas. Florida Department of Transportation. https://fdotwww.blob.core.windows.net/sitefinity/docs/defaultsource/planning/policy/ruralsupport /florida-39-s-rural-areas_finalappb.pdf?sfvrsn=ac5f9ea2_2

Pechar Diamond, E., Bonnie, R., \& Rowe, E. (2020). Rural attitudes on climate change: Lessons from national and Midwest polling and focus groups (NI Report 20-06). Nicholas Institute for Environmental Policy Solutions. https://nicholasinstitute.duke.edu/sites/default/files/publications/Rural-Attitudes-on-ClimateChange-Midwest_1.pdf

Runkle, J., Kunkel, K., Champion, S., Frankson, R., Stewart, B., \& Sweet, W. (2017). Florida state climate summary. NOAA Technical Report NESDIS 149-FL. NOAA National Centers for Environmental Information. https://statesummaries.ncics.org/chapter/fl/

UF Bob Graham Center. (2020). Barometer Florida. https://bobgrahamcenter.ufl.edu/barometer-florida/

USDA Economic Research Service. (2021). State fact sheets: Florida. https://data.ers.usda.gov/reports.aspx?StateFIPS $=12 \&$ StateName $=$ Florida $\& I D=17854$ 